\title{
Influence of age at complementary food introduction on the development of asthma and atopic dermatitis in Korean children aged $1-3$ years
}

Jihyun Lee, MD ${ }^{1}$, Meeyong Shin, MD, PhD ${ }^{1}$, Bora Lee, $\mathrm{PhD}^{2}$

${ }^{1}$ Department of Pediatrics, Soonchunhyang University Bucheon Hospital, Soonchunhyang University School of Medicine, Bucheon, Korea; ${ }^{2}$ Institute of Health \& Environment, Graduate School of Public Health, Seoul National University, Seoul, Korea

Background: Complementary food in infancy is necessary for human growth, neurodevelopment, and health. However, the role of allergen consumption in early infancy and its effects on the development of food allergy or tolerance remain unclear.

Purpose: To investigate the influence of age at the time of complementary food introduction on the development of asthma and atopic dermatitis in Korean children aged 1-3 years.

Methods: We combined data from the Korea National Health and Nutrition Examination Survey collected from 2010 to 2014 and analyzed 1619 children aged 1-3 years who were included in the survey. Multivariate regression analysis was used to identify associations among type of feeding, age at the time of complementary food introduction, and doctor-diagnosed atopic dermatitis and asthma.

Results: Age at the time of complementary food introduction was not significantly associated with doctor-diagnosed atopic dermatitis and asthma in children aged 1-3 years. In the univariate analysis, children with asthma showed higher water and sodium intake levels than nonasthmatic children. However, this relationship was not significant in the multivariate regression analysis.

Conclusion: The present study revealed no statistically significant relationship between age at the time of complementary food introduction and the risk of atopic dermatitis and asthma in young Korean children. A national prospective study is needed to clarify the influence of age at the time of complementary food introduction on the development of allergic diseases.

Key words: Complementary feeding, Asthma, Atopic dermatitis, Child

\section{Key message}

Question: Is age at the time of complementary food introduction associated with asthma and atopic dermatitis (AD) in early childhood?
Finding: We found no significant association between age at the time of complementary food introduction and the incidence of $\mathrm{AD}$ and asthma in Koreans aged 1-3 years.

Meaning: Our findings suggest that the influence of individual allergenic foods on the development of $\mathrm{AD}$ and asthma should be clarified.

\section{Introduction}

Asthma and atopic dermatitis (AD) are common chronic diseases in children worldwide. ${ }^{1)}$ Infants with $\mathrm{AD}$ may develop allergic rhinitis and/or asthma later in childhood, in a process known as the atopic march. ${ }^{2)}$ Allergic diseases are multifactorial, chronic inflammatory disorders resulting from interactions of genetic, immune, and environmental factors. Environmental factors, such as urban versus rural settings and climate, are risk factors that influence the development of these allergic diseases. Diet, breastfeeding, the timing of complementary food introduction, physical exercise, and obesity, along with factors associated with exposure to microbes, such as having pets, treatment with antibiotics, and the gut microbiome, have also been suggested to influence the development of these diseases. ${ }^{3)}$

During early infancy, the gut is first exposed to different food antigens, which may exert an influence on the development of oral immune tolerance. ${ }^{4,5}$ Complementary food in infancy is necessary for growth, neurodevelopment, and further health. ${ }^{6}$ In addition to the nutritional aspects, the introduction of complementary food in infants is also important with regard to the development of allergic diseases. ${ }^{7)}$ Until recently, it was generally considered that early exposure to solid food in infancy was associated with the development of allergies. Furthermore, prolonged exclusive breastfeeding, which is widely advocated as a preventive measure for allergic diseases, is related to delayed introduction of complementary food. The timing of complementary food introduction in infants has recently attracted increasing attention.

Corresponding author: Meeyong Shin, MD, PhD, Department of Pediatrics, Soonchunhyang University Bucheon Hospital, Soonchunhyang University School of Medicine, 170 Jomaru-ro, Bucheon 14584, Korea 
Although the mechanism underlying the maturation of the mucosal immune system is still unknown, recent studies have suggested that the early introduction of complementary food has a protective effect against the development of allergic diseases. ${ }^{8,9)}$ However, the roles of allergen consumption in early infancy and their impact on the development of allergy or tolerance to food are still controversial. A recent meta-analysis reported that the timing of solid food introduction was not associated with the development of eczema. ${ }^{10)}$

For the prevention of allergies and asthma in children, most recent guidelines recommend that infants should be exclusively breastfed for the first 4 to 6 months, with the introduction of complementary food after the age of 4 months according to normal standard weaning practices for all children regardless of atopic heredity. $6,11,12)$

This study was performed to investigate the influence of age at the introduction of complementary food on the development of asthma and $\mathrm{AD}$ in Korean children aged 1 to 3 years, and to identify possible risk factors for asthma and $\mathrm{AD}$ in young children, based on the Korea National Health and Nutrition Examination Survey (KNHANES) collected from 2010 to 2014. ${ }^{13)}$

\section{Methods}

\section{Study design and population}

We combined data from the KNHANES, a national surveillance system regarding nutrition, health, and physical examination performed by the Korea Centers for Disease Control and Prevention (KCDC), ${ }^{13)}$ collected from 2010 to 2014. The KNHANES is a cross-sectional survey conducted annually in representative non-institutionalized people in Korea, and it was approved by the Institutional Review Board of KCDC. The survey consisted of 3 components, i.e., a health interview, health examination, and nutrition survey. From among 1,619 children (2010, $\mathrm{n}=363 ; 2011, \mathrm{n}=351 ; 2012, \mathrm{n}=297 ; 2013, \mathrm{n}=311$; $2014, n=297) 1$ to 3 years old included in the survey, we excluded those for whom responses to questions about $\mathrm{AD}$ or asthma were not provided, and 1,525 children were finally selected for inclusion in this study.

\section{Variables}

Participants with a "yes" response to questions about doctordiagnosed $\mathrm{AD}$ or doctor-diagnosed asthma were classified as having $\mathrm{AD}$ or asthma, respectively. The age at diagnosis was also recorded for those with a "yes" response to the above questions.

With regard to feeding, participants were surveyed regarding age at the introduction of complementary food. Participants were divided into 3 groups based on age at introduction of complementary food: $<4$ months, 4 to 5 months, and $\geq 6$ months. Other feeding types, including breastfeeding and formula feeding, were also surveyed. The survey elicited responses as to whether the infant was breastfed, the age at introduction of breastfeeding, and the duration of breastfeeding. Similarly, with regard to formula feeding, the survey elicited responses as to whether the infant was fed formula, the age at introduction of formula feeding, and the duration of formula feeding. The survey also asked about age at the introduction of whole milk. The nutrient intake levels, including water, sodium, and fatty acids, were examined by analyzing total daily food intake. The age, sex, body mass index (BMI), and birth weight were also examined.

The KNHANES from 2011 to 2014 did not include questions about food allergies. The prevalence of allergic rhinitis was not analyzed because the diagnosis is not accurate in young children $<4$ years old.

\section{Statistical analysis}

Statistical analysis was performed with SPSS ver. 14.0 (SPSS Inc., Chicago, IL, USA). Differences in the characteristics of participants between the $\mathrm{AD}$ and non- $\mathrm{AD}$ groups and the asthma and nonasthma groups were examined using Student $t$ test and the $\chi^{2}$ test. Continuous variables are presented as means \pm standard error (SE), and categorical variables are presented as percentages \pm SE. Logistic regression analysis was used to investigate the associations between prevalence of $\mathrm{AD}$ or asthma and age at introduction of complementary food. All $P$ values of less than 0.05 were considered statistical significance.

\section{Results}

\section{Characteristics of the study population}

Tables 1 and 2 show the characteristics of the study population divided according to the diagnosis of asthma or $\mathrm{AD}$, respectively. The study population consisted of a total of 1,525 participants ranging in age from 12 to 47 months (mean \pm SE, $28.95 \pm 10.41$ months). Among the 1,525 participants, 787 (51.6\%) were male and 738 (48.4\%) were female. The prevalence rates of doctordiagnosed asthma and $\mathrm{AD}$ were $2.8 \%$ (43 of 1,525 individuals) and $10.7 \%$ (163 of 1,525 individuals), respectively. Among the participants, 23 children (1.6\%) were introduced to complementary food before 4 months, 368 (25.8\%) at 4 to 5 months, and more than half (1,034 children, $72.6 \%)$ from 6 months. Among the participants, $89.2 \%$ had been breastfed at least once.

\section{Associations between the age at introduction of complemen- tary food and the prevalence rates of asthma and $A D$}

The mean age of children with doctor-diagnosed asthma or $\mathrm{AD}$ was significantly higher than that of children without asthma or $\mathrm{AD}$ (Tables 1,2). The result was similar when adjusted for other confounding factors, such as sex, BMI, birth weight, and feeding characteristics (Tables 3,4).

None of the participants who were diagnosed with asthma started complementary food before 4 months, so the group starting complementary food from 6 months was set as the reference. Most infants (72.6\%) started complementary food from the age of 6 months. Compared with the children who started 
Table 1. Patients' demographic characteristics by asthma status

\begin{tabular}{|c|c|c|c|c|}
\hline Characteristic & Nonasthma & Asthma & All & $P$ value \\
\hline No. of subjects & 1,482 & 43 & 1,525 & \\
\hline Age (mo) & $28.78 \pm 10.41$ & $34.84 \pm 8.45$ & $28.95 \pm 10.41$ & $<0.001$ \\
\hline Sex & & & & 0.051 \\
\hline Male & $758(51.1)$ & $29(67.4)$ & 787 (51.6) & \\
\hline Female & $724(48.9)$ & $14(32.6)$ & $738(48.4)$ & \\
\hline Body mass index $\left(\mathrm{kg} / \mathrm{m}^{2}\right)$ & $16.34 \pm 1.50$ & $16.46 \pm 1.37$ & $16.34 \pm 1.50$ & 0.433 \\
\hline Birth weight (kg) & $3.21 \pm 0.46$ & $3.16 \pm 0.55$ & $3.21 \pm 0.46$ & 0.668 \\
\hline \multicolumn{5}{|l|}{ Feeding characteristics } \\
\hline Breastfeeding & & & & 0.842 \\
\hline Yes & $1,249(89.2)$ & $33(86.8)$ & $1,282(89.2)$ & \\
\hline No & $151(10.8)$ & $5(13.2)$ & $156(10.8)$ & \\
\hline Duration of BMF (mo) & $8.74 \pm 6.98$ & $7.79 \pm 6.58$ & $8.72 \pm 6.97$ & 0.430 \\
\hline Duration of BMF & & & & 0.934 \\
\hline Non & $160(11.4)$ & $5(13.2)$ & $165(11.5)$ & \\
\hline$\leq 5 \mathrm{mo}$ & $361(25.8)$ & $11(28.9)$ & $372(25.9)$ & \\
\hline 6-11 mo & $298(21.3)$ & $8(21.1)$ & $306(21.3)$ & \\
\hline$\geq 12 \mathrm{mo}$ & $580(41.5)$ & $14(36.8)$ & $594(41.3)$ & \\
\hline Formula feeding & & & & 0.984 \\
\hline Yes & $1,015(72.6)$ & $27(71.1)$ & $1,042(72.5)$ & \\
\hline No & $384(27.4)$ & $11(28.9)$ & $395(27.5)$ & \\
\hline Duration of formula feeding (mo) & $8.41 \pm 7.35$ & $8.92 \pm 7.55$ & $8.42 \pm 7.35$ & 0.727 \\
\hline Introduction of complementary food & & & & 0.844 \\
\hline Before $4 \mathrm{mo}$ & $23(1.7)$ & $0(0.0)$ & $23(1.6)$ & \\
\hline 4-5 mo & $358(25.8)$ & $10(27.0)$ & $368(25.8)$ & \\
\hline From 6 mo & $1,007(72.6)$ & $27(73.0)$ & $1,034(72.6)$ & \\
\hline \multicolumn{5}{|c|}{ Amount of intake (water, sodium, fatty acids) } \\
\hline Water intake (cup/day) & $2.30 \pm 1.71$ & $3.07 \pm 2.07$ & $2.32 \pm 1.72$ & 0.007 \\
\hline Water intake (g/day) & $590.83 \pm 318.78$ & $687.01 \pm 309.48$ & $593.36 \pm 318.81$ & 0.051 \\
\hline Sodium intake (mg/day) & $1,434.87 \pm 889.57$ & $1,913.50 \pm 1,278.33$ & $1,447.43 \pm 904.54$ & 0.010 \\
\hline Polyunsaturation fatty acid (g/day) & $5.65 \pm 4.10$ & $7.52 \pm 5.63$ & $5.71 \pm 4.18$ & 0.095 \\
\hline Omega-3 fatty acid (g/day) & $0.73 \pm 0.82$ & $0.72 \pm 0.52$ & $0.73 \pm 0.81$ & 0.752 \\
\hline Omega- 6 fatty acid (g/day) & $5.04 \pm 3.69$ & $6.90 \pm 5.19$ & $5.11 \pm 3.77$ & 0.050 \\
\hline Doctor-diagnosed AD & & & & 0.146 \\
\hline No & $1,327(89.5)$ & $35(81.4)$ & 1,362 (89.3) & \\
\hline Yes & $155(10.5)$ & $8(18.6)$ & $163(10.7)$ & \\
\hline
\end{tabular}

Values are presented as mean \pm standard error or number (\%).

$B M F$, breast-milk feeding; $A D$, atopic dermatitis.

Boldface indicates a statistically significant difference with $P<0.05$.

complementary food from 6 months, there was no significant difference in the prevalence of asthma according to the age at introduction of complementary food (Tables 1,3). In both univariate and univariate logistic regression analyses, the age at introduction of complementary food was not associated with the prevalence of $\mathrm{AD}$ (Tables 2, 4).

\section{Influence of other factors on the prevalence rates of asthma and $A D$}

In univariate analysis, the diagnosis of asthma and the diagnosis of $\mathrm{AD}$ were positively associated with each other (odds ratio [OR], 1.96), but the association was not statistically significant $(P=0.094)$. The prevalence of asthma was higher in males in univariate analysis (OR, 1.98; 95\% confidence interval [CI],
1.04-3.77; $P=0.038$ ) (Table 3). However, the difference was not significant after adjusting for confounding factors $(P=0.125)$ (Table 3). The prevalence of $\mathrm{AD}$ was also higher in males $(P=$ 0.026 ) (Table 2), and the difference remained significant after adjusting for other confounding factors (OR, 1.44; 95\% CI, 1.02-2.04; $P=0.038$ ) (Table 4).

The levels of water $(P=0.007)$ and sodium intake $(P=0.01)$ were positively associated with a diagnosis of asthma, but these relations were not significant after adjusting for confounding factors (Tables 1, 3). The duration of formula feeding was significantly inversely associated with $\mathrm{AD}$ (OR, 0.97; 95\% CI, 0.95$1.00 ; P=0.026$ ) (Table 4), but not with asthma. Other feeding characteristics, such as the type of feeding (breastfeeding or formula feeding) and duration of breastfeeding, were not associated 
Table 2. Patients' demographic characteristics by AD status

\begin{tabular}{|c|c|c|c|c|}
\hline Characteristic & Non-AD & $A D$ & All & $P$ value \\
\hline No. of subjects & 1,362 & 163 & 1,525 & \\
\hline Age (mo) & $28.72 \pm 10.47$ & $30.80 \pm 9.68$ & $28.95 \pm 10.41$ & 0.015 \\
\hline Sex & & & & 0.026 \\
\hline Male & $689(50.6)$ & $98(60.1)$ & $787(51.6)$ & \\
\hline Female & $673(49.4)$ & 65 (39.9) & $738(48.4)$ & \\
\hline Body mass index $\left(\mathrm{kg} / \mathrm{m}^{2}\right)$ & $16.36 \pm 1.48$ & $16.23 \pm 1.63$ & $16.34 \pm 1.50$ & 0.263 \\
\hline Birth weight (kg) & $3.21 \pm 0.47$ & $3.21 \pm 0.42$ & $3.21 \pm 0.46$ & 0.847 \\
\hline \multicolumn{5}{|l|}{ Feeding characteristics } \\
\hline Breastfeeding & & & & 0.785 \\
\hline Yes & 1,145 (89.0) & $137(90.1)$ & 1,282 (89.2) & \\
\hline No & $141(11.0)$ & $15(9.9)$ & $156(10.8)$ & \\
\hline Duration of BMF (mo) & $8.63 \pm 6.93$ & $9.53 \pm 7.27$ & $8.72 \pm 6.97$ & 0.152 \\
\hline Duration of BMF & & & & 0.643 \\
\hline Non & $149(11.6)$ & $16(10.7)$ & $165(11.5)$ & \\
\hline$\leq 5 \mathrm{mo}$ & $339(26.3)$ & $33(22.0)$ & $372(25.9)$ & \\
\hline 6-11 mo & $272(21.1)$ & $34(22.7)$ & $306(21.3)$ & \\
\hline$\geq 12 \mathrm{mo}$ & $527(40.9)$ & $67(44.7)$ & $594(41.3)$ & \\
\hline Formula feeding & & & & 0.272 \\
\hline Yes & $938(73.0)$ & $104(68.4)$ & $1,042(72.5)$ & \\
\hline No & $347(27.0)$ & $48(31.6)$ & $395(27.5)$ & \\
\hline Duration of formula feeding (mo) & $8.56 \pm 7.37$ & $7.27 \pm 7.11$ & $8.42 \pm 7.35$ & 0.047 \\
\hline Introduction of complementary food & & & & 0.808 \\
\hline Before $4 \mathrm{mo}$ & $21(1.6)$ & $2(1.3)$ & $23(1.6)$ & \\
\hline 4-5 mo & $328(25.7)$ & $40(26.8)$ & $368(25.8)$ & \\
\hline From 6 mo & $927(72.6)$ & $107(71.8)$ & $1,034(72.6)$ & \\
\hline \multicolumn{5}{|c|}{ Amount of intake (water, sodium, fatty acids) } \\
\hline Water intake (cup/day) & $2.32 \pm 1.75$ & $2.34 \pm 1.49$ & $2.32 \pm 1.72$ & 0.558 \\
\hline Water intake (g/day) & $591.15 \pm 319.70$ & $612.19 \pm 311.51$ & $593.36 \pm 318.81$ & 0.348 \\
\hline Sodium intake (mg/day) & $1,454.50 \pm 914.90$ & $1,387.12 \pm 811.14$ & $1,447.43 \pm 904.54$ & 0.65 \\
\hline Polyunsaturation fatty acid (g/day) & $5.74 \pm 4.21$ & $5.53 \pm 3.91$ & $5.71 \pm 4.18$ & 0.875 \\
\hline Omega-3 fatty acid (g/day) & $0.73 \pm 0.83$ & $0.66 \pm 0.64$ & $0.73 \pm 0.81$ & 0.405 \\
\hline Omega-6 fatty acid (g/day) & $5.13 \pm 3.81$ & $4.96 \pm 3.43$ & $5.11 \pm 3.77$ & 0.888 \\
\hline Doctor-diagnosed asthma & & & & 0.146 \\
\hline No & $1,327(97.4)$ & $155(95.1)$ & $1,482(97.2)$ & \\
\hline Yes & $35(2.6)$ & $8(4.9)$ & $43(2.8)$ & \\
\hline
\end{tabular}

Values are presented as mean \pm standard error or number (\%).

$B M F$, breast-milk feeding; AD, atopic dermatitis.

Boldface indicates a statistically significant difference with $P<0.05$.

with the prevalence of asthma and $\mathrm{AD}$. The levels of polyunsaturated fatty acid and omega- 3 and omega- 6 fatty acid intake were not related to the development of asthma or $\mathrm{AD}$.

\section{Discussion}

This study was performed using the KNHANES data collected from 2010 to 2014 to investigate the influence of age at the introduction of complementary food on the development of asthma and AD. Our data showed no significant differences in the prevalence rates of asthma and $\mathrm{AD}$ according to the age at introduction of complementary food.

The introduction of complementary food in infants involves exposure to allergens that may impact the intestinal microbiota as well as the future development of allergic diseases. ${ }^{714)}$ The effect has not been clarified, and recommendations regarding the optimal timing for the introduction of infants to solid food have been changing. ${ }^{15)}$ In the past, it was recommended that the introduction of solid food should be delayed to around 6 months of age for children at high risk of allergic diseases, and highly allergenic foods, such as peanuts, fish, and seafood, should be introduced later. ${ }^{16}$ However, recent studies have indicated that early introduction of complementary food is beneficial to reduce the risk of allergic diseases, ${ }^{14,17)}$ or introducing solid food after 4 months of age does not protect against food allergies. ${ }^{11,18)}$ In one case-control study performed in Italy, compared to the exclusive breastfeeding group, children with early introduction of comple- 
Table 3. Adjusted association between studied variables and asthma

\begin{tabular}{|c|c|c|c|c|}
\hline \multirow{2}{*}{ Characteristic } & \multicolumn{2}{|c|}{ Univariate logistic regression } & \multicolumn{2}{|c|}{ Multiple logistic regression } \\
\hline & OR $(95 \% \mathrm{Cl})$ & $P$ value & OR $(95 \% \mathrm{Cl})$ & $P$ value \\
\hline Age (mo) & $1.06(1.03-1.1)$ & $<0.001$ & $1.05(1.02-1.09)$ & 0.005 \\
\hline \multicolumn{5}{|l|}{ Sex } \\
\hline Female & 1.00 & - & 1.00 & - \\
\hline Male & $1.98(1.04-3.77)$ & 0.038 & $1.71(0.86-3.41)$ & 0.125 \\
\hline \multicolumn{5}{|c|}{ Introduction of complementary food } \\
\hline Before $4 \mathrm{mo}$ & 0 (0-Inf) & 0.985 & - & - \\
\hline 4-5 mo & $1.04(0.5-2.17)$ & 0.913 & - & - \\
\hline From 6 mo & 1.00 & - & & \\
\hline Water intake (cup/day) & $1.17(1.04-1.32)$ & 0.010 & $1.11(0.97-1.28)$ & 0.136 \\
\hline Sodium intake (mg/day) & $1.0004(1.0001-1.0006)$ & 0.002 & $1.0002(1-1.0005)$ & 0.080 \\
\hline \multicolumn{5}{|l|}{ Doctor-diagnosed AD } \\
\hline No & 1.00 & - & - & - \\
\hline Yes & $1.96(0.89-4.29)$ & 0.094 & - & - \\
\hline
\end{tabular}

OR, odds ratio; $\mathrm{Cl}$, confidence interval; $\mathrm{AD}$, atopic dermatitis.

Boldface indicates a statistically significant difference with $P<0.05$.

Table 4. Adjusted association between studied variables and atopic dermatitis

\begin{tabular}{|c|c|c|c|c|}
\hline \multirow{2}{*}{ Characteristics } & \multicolumn{2}{|c|}{ Univariate logistic regression } & \multicolumn{2}{|c|}{ Multiple logistic regression } \\
\hline & OR (95\% Cl) & $P$ value & OR $(95 \% \mathrm{Cl})$ & $P$ value \\
\hline Age (mo) & $1.02(1-1.04)$ & 0.016 & $1.02(1-1.04)$ & 0.029 \\
\hline \multicolumn{5}{|l|}{ Sex } \\
\hline Female & 1.00 & - & 1.00 & - \\
\hline Male & $1.47(1.06-2.05)$ & 0.022 & $1.44(1.02-2.04)$ & 0.038 \\
\hline Duration of formula feeding & $0.98(0.95-1)$ & 0.044 & $0.97(0.95-1)$ & 0.026 \\
\hline \multicolumn{5}{|c|}{ Introduction of complementary food } \\
\hline Before $4 \mathrm{mo}$ & $0.62(0.15-2.63)$ & 0.516 & - & - \\
\hline 4-5 mo & $1.06(0.72-1.55)$ & 0.779 & - & - \\
\hline From 6 mo & 1.00 & - & - & - \\
\hline \multicolumn{5}{|l|}{ Doctor-diagnosed asthma } \\
\hline No & 1.00 & - & - & - \\
\hline Yes & $1.96(0.89-4.29)$ & 0.094 & - & - \\
\hline
\end{tabular}

$\mathrm{OR}$, odds ratio; $\mathrm{Cl}$, confidence interval.

Boldface indicates a statistically significant difference with $P<0.05$.

mentary food at 4 and 5 months had a lower $\mathrm{AD}$ risk (OR, 0.41; 95\% CI, 0.20-0.87 and OR, 0.39; 95\% CI, 0.18-0.83, respectively). ${ }^{17}$

Based on the results of recent birth cohort studies, most recent guidelines recommend that the introduction of complementary food should not be delayed for prevention of allergic diseases, regardless of atopic heredity. The World Health Organization recommends exclusive breastfeeding up to 6 months of age, but this is not specifically aimed at reducing the risk of allergic diseases. ${ }^{11)}$ The guidelines of the European Academy of Allergy and Clinical Immunology for the prevention of food allergy and anaphylaxis in 2014 recommended exclusive breastfeeding for at least the first 4 to 6 months of life, and introduction of complementary food after the age of 4 months for all infants, regardless of atopic heredity. ${ }^{19)}$ Therefore, we expected that early introduction of complementary food would reduce the risk of asthma and $\mathrm{AD}$ development. However, the results of the present study indicated that early introduction before 4 months was not associated with a reduced risk of asthma and $\mathrm{AD}$ development in early childhood. The prevalence rates of asthma and $\mathrm{AD}$ were also not associated with the timing of complementary food when participants were divided into 2 groups: introduction of solid food before versus after 6 months of age (data not shown). The proportion of participants who started complementary food before 4 months of age was only $1.6 \%$, so we divided the participants differently and reanalyzed: $<6$ months, 6 to 9 months, and $\geq 10$ months based on age at introduction of complementary food. Compared with the children who started complementary food before 6 months of age, there was a trend of increased prevalence of asthma in children who started complementary food from 10 months of age, but it was not statistically significant (data not shown). In a recent systemic review, there was no relationship between the age when complementary feeding first begins and the risk of developing $\mathrm{AD} /$ eczema or asthma. ${ }^{20)}$

There is accumulating evidence that early introduction of solid 
food can reduce the risk of general food allergy. ${ }^{21,22)}$ In a randomized control study in the United Kingdom called the Enquiring About Tolerance study, the prevalence of any food allergy at the age of 1 to 3 years old was significantly lower in the early introduction group than in the standard introduction group. ${ }^{21)}$

Some studies indicated that early supplementation of specific food allergens could prevent allergy to that food allergen. The Learning Early About Peanut (LEAP) study, demonstrated a significant reduction in the development of peanut allergy with early peanut introduction. ${ }^{22)}$ Similar to the LEAP study, 2-step egg introduction for Prevention of Egg Allergy in High-risk Infants with Eczema study showed that the early introduction of heated egg is an efficacious way to prevent hen's egg allergy in high-risk infants. ${ }^{23)}$

In most of participants in this study (72.6\%) complementary food was introduced relatively late, from the age of 6 months, with only $25.8 \%$ of children starting solid food at 4 to 5 months. Similar to our results, in a study performed in Singapore in which infants were introduced to egg (49.6\%), peanut (88.7\%), and shellfish (90.2\%) after the age of 10 months, ${ }^{24)}$ food allergy rates were low despite delayed introduction of allergenic foods, suggesting that early introduction of allergenic foods may not be important in some populations.

There have been conflicting reports regarding the preventive effect of breastfeeding against the development of AD. Many studies have reported that breastfeeding reduces the risk of $A D .{ }^{25-28)}$ A birth cohort study reported that breastfeeding for $\geq 6$ months, including partial breastfeeding, was significantly associated with reduced risk of eczema but not allergic rhinitis and asthma, and partial breastfeeding for $<6$ months was associated with increased risk of eczema at ages 1 and 2 years. ${ }^{25)}$ In the present study, the type of feeding (breastfeeding or formula feeding) and duration of breastfeeding were not associated with the prevalence of $\mathrm{AD}$ and asthma. Most children had been breastfed at least once (89.2\%) and $27.5 \%$ of participants were exclusively breastfed. A previous study based on the KNHANES data collected from 2007 to 2012 also reported that breastfeeding was not associated with the occurrence of $\mathrm{AD}$ in early childhood. ${ }^{29)}$ Unexpectedly, in the present study, the duration of formula feeding was shorter in children with $\mathrm{AD}$ than in those without $\mathrm{AD}$. This may be attributable to the fact that many parents of children with $\mathrm{AD}$ try to avoid feeding formula in Korea.

Along with age at introduction of complementary food, other factors are likely to have complex and important impacts on the development of allergic diseases. It has been reported that the diversity of food consumed in early life has important effects on the incidence of allergic diseases. Recent studies have indicated that reduced food diversity during infancy may increase the risk of allergic diseases in childhood.,30) A Finnish Birth Cohort study, which analyzed data of 3,142 children, reported that reduced diversity of food introduced during the first year after birth increased the risk of asthma and allergies in childhood. ${ }^{30}$ However, the KNHANES did not survey the diversity of complementary food and so this could not be analyzed in the present study. Therefore, we could not definitively conclude that complementary food does not influence the development of asthma and $\mathrm{AD}$.

$\mathrm{AD}$ is usually the first symptom of allergic diseases, with subsequent development of food allergy, rhinitis, and asthma, which is referred to as the atopic march. The association between $\mathrm{AD}$ and asthma is well known, and $\mathrm{AD}$ is considered a risk factor for the development of asthma. However, our study did not show a significant correlation between the development of asthma and $\mathrm{AD}$, which is thought to be related to the fact that our study population consisted of young children 1 to 3 years old. Asthma develops later than $\mathrm{AD}$, so it is possible that there had been insufficient time for asthma to have developed in some of these infants.

The KNHANES includes questions regarding the intake of nutritional components, such as polyunsaturated fatty acid, omega-3 and omega- 6 fatty acids, and daily levels of water and sodium intake. Therefore, we analyzed their associations with the prevalence of asthma and $\mathrm{AD}$, but our results did not indicate any significant associations.

The present study had some limitations. First, this was a crosssectional study and, therefore, it was more limited in the ability to analyze causal relationships compared to prospective cohort studies. Second, although the survey was performed by trained interviewers, there may have been recall bias. Third, genetics and familial history are also important risk factors in the development of allergic diseases, but they were not taken into consideration in this study because the KNHANES did not include questions related to familial allergic history. Despite these limitations, the major strength of this study was that the KNHANES is conducted in a nationally representative population, and this is the first Korean study regarding the association between age at introduction of complementary food and the development of asthma and $\mathrm{AD}$ in early childhood.

The present study showed no statistically significant relationships between age at introduction of complementary food and the risks of $\mathrm{AD}$ and asthma in early childhood in Korean children. Most infants started solid food from the age of 6 months. A further national prospective study is needed to clarify the further influence of age at the introduction of complementary food in the development of allergic diseases, as well as the influence of the introduction of individual allergenic foods.

\section{Conflicts of interest}

No potential conflict of interest relevant to this article was reported.

\section{Acknowledgments}

This work was supported by the Soonchunhyang University Research Fund. This study was presented at the 2017 American Academy of Allergy, Asthma \& Immunology (AAAAI) Annual Meeting, March 3-6, 2017, Atlanta, GA, USA (conference abstract No. 436). 


\section{ORCID}

Jihyun Lee @ https://orcid.org/0000-0001-8750-193X

Meeyong Shin (1) https://orcid.org/0000-0003-3699-8741

\section{References}

1. Mallol J, Crane J, von Mutius E, Odhiambo J, Keil U, Stewart A. The International Study of Asthma and Allergies in Childhood (ISAAC) Phase Three: a global synthesis. Allergol Immunopathol (Madr) 2013;41:73-85.

2. Spergel JM. From atopic dermatitis to asthma: the atopic march. Ann Allergy Asthma Immunol 2010;105:99-106; quiz 7-9, 17.

3. Nutten S. Atopic dermatitis: global epidemiology and risk factors. Ann Nutr Metab 2015;66 Suppl 1:8-16.

4. Roduit C, Frei R, Depner M, Schaub B, Loss G, Genuneit J, et al. Increased food diversity in the first year of life is inversely associated with allergic diseases. J Allergy Clin Immunol 2014;133:1056-64.

5. West CE, Videky DJ, Prescott SL. Role of diet in the development of immune tolerance in the context of allergic disease. Curr Opin Pediatr 2010; 22:635-41.

6. Agostoni C, Decsi T, Fewtrell M, Goulet O, Kolacek S, Koletzko B, et al. Complementary feeding: a commentary by the ESPGHAN Committee on Nutrition. J Pediatr Gastroenterol Nutr 2008;46:99-110.

7. Kozyrskyj AL, Bahreinian S, Azad MB. Early life exposures: impact on asthma and allergic disease. Curr Opin Allergy Clin Immunol 2011;11: 400-6.

8. Nwaru BI, Takkinen HM, Niemelä O, Kaila M, Erkkola M, Ahonen S, et al. Timing of infant feeding in relation to childhood asthma and allergic diseases. J Allergy Clin Immunol 2013;131:78-86.

9. Sariachvili M, Droste J, Dom S, Wieringa M, Hagendorens M, Stevens $\mathrm{W}$, et al. Early exposure to solid foods and the development of eczema in children up to 4 years of age. Pediatr Allergy Immunol 2010;21:74-81.

10. Waidyatillake NT, Dharmage SC, Allen KJ, Bowatte G, Boyle RJ, Burgess JA, et al. Association between the age of solid food introduction and eczema: a systematic review and a meta-analysis. Clin Exp Allergy 2018; 48:1000-15.

11. Tarini BA, Carroll AE, Sox CM, Christakis DA. Systematic review of the relationship between early introduction of solid foods to infants and the development of allergic disease. Arch Pediatr Adolesc Med 2006;160: 502-7.

12. Australasian Society of Clinical Immunology and Allergy. ASCIA Guidelines: Infant feeding and allergy prevention [Internet]. Brookvale (AU): ASCIA; 2016 [cited by 2020 May 1]. Available from: https://www. allergy.org.au/images/pcc/ASCIA_guidelines_infant_feeding_and_ allergy_prevention.pdf.

13. Kweon S, Kim Y, Jang MJ, Kim Y, Kim K, Choi S, et al. Data resource profile: the Korea National Health and Nutrition Examination Survey (KNHANES). Int J Epidemiol 2014;43:69-77.

14. Joseph CL, Ownby DR, Havstad SL, Woodcroft KJ, Wegienka G, MacKechnie $\mathrm{H}$, et al. Early complementary feeding and risk of food sensitization in a birth cohort. J Allergy Clin Immunol 2011;127:1203-10.e5.

15. Koplin JJ, Allen KJ. Optimal timing for solids introduction - why are the guidelines always changing? Clin Exp Allergy 2013;43:826-34.

16. American Academy of Pediatrics. American Academy of Pediatrics. Committee on Nutrition. Hypoallergenic infant formulas. Pediatrics 2000; 106:346-9.
17. Turati F, Bertuccio P, Galeone C, Pelucchi C, Naldi L, Bach JF, et al. Early weaning is beneficial to prevent atopic dermatitis occurrence in young children. Allergy 2016;71:878-88.

18. Sausenthaler S, Heinrich J, Koletzko S. Early diet and the risk of allergy: what can we learn from the prospective birth cohort studies GINIplus and LISAplus? Am J Clin Nutr 2011;94(6 Suppl):2012S-2017S.

19. Muraro A, Halken S, Arshad SH, Beyer K, Dubois AE, Du Toit G, et al. EAACI food allergy and anaphylaxis guidelines. Primary prevention of food allergy. Allergy 2014;69:590-601.

20. Obbagy JE, English LK, Wong YP, Butte NF, Dewey KG, Fleischer DM, et al. Complementary feeding and food allergy, atopic dermatitis/eczema, asthma, and allergic rhinitis: a systematic review. Am J Clin Nutr 2019; 109:890s-934s.

21. Perkin MR, Logan K, Tseng A, Raji B, Ayis S, Peacock J, et al. Randomized trial of introduction of allergenic foods in breast-fed infants. N Engl J Med 2016;374:1733-43.

22. Du Toit G, Roberts G, Sayre PH, Bahnson HT, Radulovic S, Santos AF, et al. Randomized trial of peanut consumption in infants at risk for peanut allergy. NEngl J Med 2015;372:803-13.

23. Natsume O, Kabashima S, Nakazato J, Yamamoto-Hanada K, Narita M, Kondo $\mathrm{M}$, et al. Two-step egg introduction for prevention of egg allergy in high-risk infants with eczema (PETIT): a randomised, double-blind, placebo-controlled trial. Lancet 2017;389:276-86.

24. Tham EH, Lee BW, Chan YH, Loo EXL, Toh JY, Goh A, et al. Low food allergy prevalence despite delayed introduction of allergenic foods-data from the GUSTO Cohort. J Allergy Clin Immunol Pract 2018;6:466-75. e1.

25. Chiu CY, Liao SL, Su KW, Tsai MH, Hua MC, Lai SH, et al. Exclusive or partial breastfeeding for 6 months is associated with reduced milk sensitization and risk of eczema in early childhood: The PATCH Birth Cohort Study. Medicine (Baltimore) 2016;95:e3391.

26. Kull I, Wickman M, Lilja G, Nordvall SL, Pershagen G. Breast feeding and allergic diseases in infants-a prospective birth cohort study. Arch Dis Child 2002;87:478-81.

27. Kull I, Böhme M, Wahlgren CF, Nordvall L, Pershagen G, Wickman M. Breast-feeding reduces the risk for childhood eczema. J Allergy Clin Immunol 2005;116:657-61.

28. Bener A, Ehlayel MS, Alsowaidi S, Sabbah A. Role of breast feeding in primary prevention of asthma and allergic diseases in a traditional society. Eur Ann Allergy Clin Immunol 2007;39:337-43.

29. Lee KS, Rha YH, Oh IH, Choi YS, Kim YE, Choi SH. Does breast-feeding relate to development of atopic dermatitis in young Korean children? Based on the Fourth and Fifth Korea National Health and Nutrition Examination Survey 2007-2012. Allergy Asthma Immunol Res 2017;9:30713.

30. Nwaru BI, Takkinen HM, Kaila M, Erkkola M, Ahonen S, Pekkanen J, et al. Food diversity in infancy and the risk of childhood asthma and allergies. J Allergy Clin Immunol 2014;133:1084-91.

How to cite this article: Lee J, Shin M, Lee B. Influence of age at complementary food introduction on the development of asthma and atopic dermatitis in Korean children aged 1-3 years. Clin Exp Pediatr 2021;64:408-14. https://doi.org/10.3345/cep. 2020.01382 